\title{
Perception of educational value in clinical rotations by medical students
}

This article was published in the following Dove Press journal:

Advances in Medical Education and Practice

9 February 2017

Number of times this article has been viewed

\author{
David A Kandiah \\ School of Psychiatry and Clinical \\ Neurosciences, Faculty of Medicine, \\ Dentistry and Health Sciences, \\ University of Western Australia, Perth, \\ WA, Australia
}

Aim: Clinical teaching in Australian medical schools has changed to meet the needs of substantially increased medical student cohorts. As such, formal feedback from these student cohorts is needed about the value they place on the educational input from each clinical rotation. This study aims to determine which aspects of clinical placements are most educationally useful to medical students. Methods: In this study, final year medical students from the University of Western Australia (UWA) were surveyed via an anonymous online questionnaire, identifying which clinical placements were found to be the most and the least useful to their learning and the positive aspects of these placements. Two focus groups were conducted prior to the design of the questionnaire to determine the key areas of focus important to medical students. Ethics approval for this study was obtained from the UWA Human Research Ethics Committee.

Results: Our focus groups were consistent in finding that students enjoyed placements where they were included as a part of the medical team and played a role in patient care. This was consistent with the concept that inclusiveness and participation in the clinical setting are important in developing competence in tasks and skills. The ratio of students to doctors was crucial, with a low ratio given a higher rating as seen in the rural clinical school.

Conclusion: The results of this project could benefit both the local and national medical curricula in identifying the most effective clinical attachments for learning and preparation for prevocational training. This is relevant especially due to the limited number of clinical placements and growing cohort of medical students. The results of this study can also be extrapolated to international medical education.

Keywords: educational value, clinical rotations, medical students, satisfaction

\section{Introduction}

Medical students experience a variety of different learning environments throughout their medical course, from structured lectures and tutorials, group or team-based peer-assisted learning sessions to clinical community and hospital-based attachments. Students' perceived value from these experiences vary greatly and need to be evaluated in order to determine the most effective environments for learning. Failure to integrate student input regarding effective teaching and learning methods can lead to the disproportionate allocation of resources to methods with less value and effectiveness.

\section{Evolving medical education in Australia: changes in student numbers and workforce needs}

The changing landscape of medical education in Australia has meant that the number of medical students and graduates is rising significantly. ${ }^{1}$ Insufficient medical work-
Correspondence: David A Kandiah School of Psychiatry and Clinical Neurosciences, Faculty of Medicine, Dentistry and Health Sciences, University Bondi Junction, Sydney, NSW I355, Australia

Tel +6 | $448801|4|$

Fax +61290341241

Email davidkandiah@doctor.com 
force numbers, an aging medical workforce and increasing rates of chronic diseases have driven the increase in the number of medical schools and medical students in recent years. ${ }^{1}$ From 2004 to 2012, the number of medical students graduating was reported to be more than doubled, from 1500 to $\sim 3700$. $^{2}$ The development of competent medical graduates relies on adequate, well-supervised training. Unfortunately, the increase in the number of students has not been matched by a proportionate increase in the number of medical educators and clinical learning placements. ${ }^{3,4}$ Consequently, there are increasing constraints on educational time and value for each student.

\section{Five solutions for limited resources}

1. Increase the number of trained medical educators across the spectrum from interns to consultants. Developed and established supervisory programs could be used to engage these doctors.

2. Increase the utilization of available resources. For this to occur, the aspects of clinical placements that provide the most educational value to students need to be identified, as we have explored in this study.

3. Data from this study and others can be used to develop new collaborations and cultivate new teaching and supervisory relationships with other health professionals. Key areas where this could be established include supervision of practical procedures, e.g., venesections, cannulations, urinary catheterizations and nasogastric tube insertions.

4. Optimize case mix and patient encounters with a blend of metropolitan, regional and rural clinical placements.

5. Maximize modern technology to equilibrate learning opportunities across clinical placements, e.g., with videoconferencing, e-learning, discussion boards and social media. Student learning from experienced and expert clinical practitioners can occur despite issues with distance and time zones.

\section{What do medical students and junior doctors want and need in their clinical learning?}

Educational value to medical students may come in the form of adequate training in clinical, technical, analytical, communication and management skills. It also includes effective learning from participation and engagement. Quality supervision has been identified as a key factor for maximizing the educational value of clinical learning. ${ }^{5}$ Supervisors who are experienced and engaging make students more interested in critically analyzing patients' clinical conditions, studying them and utilizing this work to formulate management plans. ${ }^{6}$ When supervision is disorganized and not constructive, students become frustrated and lose interest in clinical learning. A quality supervisor who increases the educational value for students is someone who is knowledgeable, skilfull and able to encourage a problem-solving approach. ${ }^{7}$ Effective learning in the clinical setting can be enhanced by encouragement or invitation to students to engage in interactions with peers and practitioners and to participate fully as a member of the health care team. Useful and constructive feedback from clinical teachers may also enhance the educational value for students. ${ }^{8}$

Previous studies investigating the factors that are most important in creating effective learning environments for junior doctors found that the level of participation students are afforded in the workplace is key in clinical practice learning. ${ }^{9}$ It has been established that greater participation in the workplace facilitates greater confidence and competency, especially in clinical practice. , $^{1,9}$

A 2006 American study that sought to identify key variables perceived by students to be associated with educationally valued surgical clerkship sites found that direct patient care experiences, teaching during rounds, opportunities to practice procedures and skills and average hours per week of teaching by attending doctors contributed significantly to overall educational value. ${ }^{10}$ The variables that were found not to contribute to overall educational value included outpatient exposure, conferences and feedback.

A 1997 study from Ireland that looked at the intern education and training program found that a majority of interns considered that they were not prepared for all the skills/competencies needed as an intern. ${ }^{11}$ It identified that work experience, rather than formal training, helped them to acquire skills and professional competencies. The staff that helped them the most were nonconsultant hospital doctors and fellow interns. It was also noted that placements that are too specialized, such as cardiothoracic surgery, have limited value because the experience is mainly clerical and the duties are nonclinical. In regard to learning needs in the undergraduate clinical curriculum, the study found that graduates considered that their clinical experience had been too variable, too fragmented and, for some attachments, too specialized. Graduates also felt that their roles and duties were not clearly defined and that their exposure to common clinical problems was inadequate.

A 2008 study from South Africa investigating the perceived educational value of a 2 -week rural clinical rotation 
for medical students in South Africa found three criticisms from students. 1) The rural rotation was not structured efficiently; 2) compulsory written reports and additional projects prevented them from maximizing the rural experience; and 3) a time period of 2 weeks was felt to be too short for optimum benefit from the rotation. ${ }^{12}$

\section{Medical education in nonmetropolitan clinical placements}

The shortage of doctors in remote areas in Australia is a challenge for the health care system. Medical schools have addressed this need by developing rural-based teaching opportunities, with government funding allocated for rural clinical schools (RCSs) and rural placements. ${ }^{13}$ These placements aim to expose medical students to rural practice, encouraging them to work in geographical areas of need as graduates. It is thought that exposure to rural clinical practice in a doctor's medical training is an important influence in determining whether they choose careers as rural health care providers. ${ }^{14}$ This philosophy also reduces the burden of clinical teaching in metropolitan health services, allowing for greater student-clinician and student-patient interaction. Allowing students to spend time in rural communities allows students to understand the role of a rural physician and to experience the unique opportunities available outside of metropolitan health care settings. A review of the literature regarding the impact of rural clinical experiences and future career choice found that the majority of studies showed they had a positive influence upon students to consider primary care specialities and choosing rural practice. ${ }^{14}$

\section{Academic performance of rural students}

Comparing the academic performance of rural and metropolitan medical students, a cohort study of medical students from Flinders University found the view that student academic performance in the tertiary hospital setting exceeding that of students in the regional hospital and community settings is not justified. ${ }^{15}$ In fact, the study's results showed that students in the rural program outperformed metropolitan students academically. In contrast, a 1996 Western Australian study found that there was no statistically or clinically significant difference in the mean marks of rural students compared with metropolitan students. ${ }^{16}$ The study did, however, note that almost all rural students (25 out of 28) saw a wider variety of patients and more clinical problems and conditions than metropolitan students and they also participated in six times the number of procedures.

\section{Assessments and impact on clinical learning}

Students have reported frequent assessments in medical school mean that a lot of their time is spent preparing for the next examination rather than getting the most out of their clinical years in hospital-based learning environments. A study conducted by Newble and Jaeger ${ }^{17}$ in 1983 described a scenario where medical students reported that they spent too much time studying theoretical components of the course compared to the practical and clinical aspects of medicine. Action was taken by the faculty to develop a new examination regime that reflected more on aspects of clinical learning rather than just theory. Students surveyed after the course change found that the nature of clinical scenarios in the new examinations was a better assessment of their clinical competence and as such, they were able to get more out of their clinical learning environment, since an increase in ward-based learning activities was vital for success in such examinations. The new clinical examination had therefore influenced the students' learning in a positive way and such positive influence may still be achieved if the current course takes the views of students on the frequency of assessments and the negative impact this can have on their learning.

\section{Development of research project}

The aim of this research was to identify strengths and weaknesses in current Australian medical student education. This was performed from the perceptions of the actual consumers, the students themselves. This study was conducted in the following two parts:

1. Focus groups to explore current students' experiences and perception of educational value from their clinical placements.

2. An online questionnaire to quantify their responses and stratify differences between students who had completed at least 1 year in a rural clinical setting versus those that had completed most of their training in a metropolitan setting.

\section{Methods}

Two focus groups were conducted, the first involving sixthyear University of Western Australia (UWA) medical students and the second involving medical students participating in the Australian Medical Students' Association (AMSA) 
leadership council who were from various year groups and medical schools in Australia. The aim was to gather in depth information about students' experiences and perspectives on teaching and learning in clinical placements and assessment in the medical course. Sixth-year medical students from UWA were invited to join the focus group via email. Sixth-year students who spent their fifth year participating in the RCS program were included, allowing for comparison between the experiences of these students and those who were metropolitan students in their fifth year. Three main questions were asked by the focus group facilitator and left open for discussion among the participants. These questions include the folllowing:

1. A) What were the placements that you found educationally useful?

B) Why did you find these placements useful?

2. A) What were the placements that you found enjoyable?

B) Why did you find these placements enjoyable?

3. A) What is your ideal learning environment?

B) What is the actual learning environment?

The common themes that arose from the focus groups helped define the different components of the questionnaire. The focus groups' responses were recorded by three different scribes to make sure that all the discussion responses were noted. A debriefing session was conducted straight after to collate all the responses to the questions. Thematic analysis was used to capture the rich, detailed and complex account of the data. The analysis focused on a description of the whole data set. ${ }^{18} \mathrm{~A}$ theoretical thematic analysis was performed based on previous literature reviews. ${ }^{19}$ The main themes that were derived from the analysis were prior learning in medical program, clinical placements in metropolitan versus rural sites, maximizing value of interaction with clinicians and methods of interaction including assessment of performance. More details are provided in the "Results" section.

The study population consisted of final year (sixth-year) medical students from the UWA, who were recruited via email to fill in an online questionnaire. An initial recruitment email and three subsequent reminder emails were sent to the cohort's university email accounts, inviting them to fill in a questionnaire on Survey Monkey, an online questionnaire website, by following a link contained in the email. The Questionnaire developed had the following four parts:

1. Part $\mathrm{A}$ - gathering background information including whether the respondent was in the undergraduate or graduate course and expected year of graduation.

2. Part B - determining the length of the respondent's medical curriculum, including premedical, preclinical and clinical phases, the amount of integration of clinical and medical sciences in the course and ratings of different learning characteristics in the curriculum.

3. Part $\mathrm{C}$ - assessing clinical rotations, including participation in RCS, which rotations were most educationally useful and why they were useful.

4. Part D-determining which aspects of teaching were most useful and what type of assessments were commonly used during clinical rotations.

Respondents were also allowed to provide free text written comments on any other useful educational encounters they experienced.

Questions in Parts C and D asked respondents to rate clinical attachments and aspects of teaching and learning using 5-point Likert scale. The allocated ratings were

1. Not useful at all

2. Rarely useful ( $<10 \%$ of the time)

3. Minimally useful $(10 \%-30 \%$ of the time $)$

4. Moderately useful $(40 \%-80 \%$ of the time $)$

5. Very useful ( $>80 \%$ of the time)

6. Not applicable

Participants were recruited through a total of four emails. The initial recruitment email raised 22 responses. Three subsequent reminder emails raised $\sim 10$ additional students each time. This generated a total response from 54 students out of an eligible cohort of 160 students. This represented 33.8\% of all registered final year medical students in this cohort.

Recruitment emails were sent together with an information form pertaining to the study aims, the ethics approval and the contact details for the research supervisor of the study. As the study was anonymous, participants provided informed consent for their data to be used in the study according to the Ethics approval, by completion of the questionnaire. The Faculty Information Technology Officer matched the emails to the questionnaires to confirm that no student completed this more than once. Neither incentives nor financial rewards were offered or given to students who completed the questionnaire.

The pattern of response rate was very similar following each recruitment email. The responses generated from each email all came within the first few days after the email.

Both descriptive and inferential statistical analysis was performed on the relevant questionnaire responses. Rating averages were generated for questions for which they would provide meaningful results. The rating averages had to be adjusted using a simple algorithm, for the questions in which participants could answer not applicable (NA), so that they were a true reflection of the responses. 


\section{Ethics}

The project had already gained ethics approval from Scientific Research and Ethics committee of the Medical Deans of Australia and New Zealand, which also supported this project. The AMSA has also supported this research and one of the focus groups was conducted at their Annual Congress in 2013. Ethics approval was given by the UWA Human Research Ethics Committee (RA/4/1/5326).

\section{Results and analysis Focus group reports UWA focus group}

The initial focus group conducted involved four sixth-year UWA medical students, three of whom participated in the RCS placement during their fifth year of study.

Students who took part in RCS found it an enjoyable experience that had advantages over teaching in metropolitan tertiary hospitals. Aspects of RCS, which were favorable, included being able to interact with doctors on a closer basis professionally and socially, the smaller student-teacher ratio, the presence of doctors that were more invested in students' learning, the ability to develop a long-term relationship with doctors (metropolitan students change rotation every 8 weeks, while RCS students have an 11-month continuous contact with the same doctors) and the ability to generate a greater rapport with patients and be involved in their follow-up.

Students felt that participation in outpatient clinics and bedside tutorials were valuable to their learning. Clinics and bedside tutorials allow for students to receive feedback from senior doctors on their examination technique and then be questioned about clinical findings, diagnoses and management.

Students found that business ward rounds were of little benefit, as they were often only able to observe and not actively participate. Ward rounds are important in the organization of patient care in hospitals but are often not the ideal environment to develop practical skills or clinical reasoning due to time constraints faced by consultants and senior doctors.

Aspects of teaching that were found to be most useful revolve around student participation in patient care. The ideal learning environment involved students being included as a part of a team and able to contribute to management plans, allowing them to gain confidence and develop skills to be prepared to work as an intern. The best approach seemed to be when students were able to see a patient and conduct an appropriate history and clinical examination, then present to a senior doctor and receive feedback, discuss a management plan and be asked questions. This was felt to increase student's medical competency and communication skills. Being able to follow-up patients to discharge was the ideal ending to these scenarios where the student would be able to see how effective the management plan was, its implementation and the results.

Students identified that assessments should be relevant to teaching. Assessments functioned as a useful learning tool if they were designed to solidify knowledge and point out gaps in their learning. Assessing knowledge that was too specific or not commonly encountered on rotations placed pressure on students in their study and would frustrate and hamper their confidence. Too many written assessments also caused students to reduce the amount of patient contact they experience while on placements as they spend time completing these.

\section{AMSA Leadership Council focus group}

Thirteen students participated in this focus group voluntarily, comprised of a mix of graduate and undergraduate students throughout Australia from the Universities of New South Wales, Newcastle, Adelaide, Wollongong, Queensland, Tasmania, Monash and Deakin Universities, and a postgraduate doctor in an Obstetrics-Gynecology training program.

The participants agreed that clinical rotations were more effective when they were "hands on". This correlated with smaller team sizes and when students were included in the team, often doing jobs that the intern would normally do. Overall the more engaged the student was, the more beneficial they felt that particular rotation was. The most favored rotation was the emergency room as students were able to perform the job of an intern and were not dependent on the medical team to provide them with educational experiences as they are constantly exposed to learning opportunities.

Outpatient clinics were thought to be less educationally useful as there would often be less patient exposure, as only a few patients may be seen in a session. They were useful when the students were allowed to see the patient one-on-one, formulate their own diagnosis and management plan and then discuss with the treating doctor. Allied health clinics were thought to be too specialized a placement. Students felt that placements should be more general instead of being too specialized as this allows for development of a wider range of skills and observing a broad range of clinical problems and diseases.

However, allied health exposure was seen to be important as it allows students to understand their roles better and increase confidence in communication. Students were able to 
see how a multidisciplinary team works and were made aware of the services that are available for doctors to refer patients to. Students felt that they would benefit from completing these placements early on in their medical education, as they would serve as an appropriate introduction into the clinical teaching environment. This would require an appropriate educational structure and encourage the students to become involved.

The ideal learning environment would be when students are held accountable (e.g., allocated patients to clerk when their team is on take) and have some responsibility in the team, as they were more encouraged and motivated to be involved and found that learning is generally more effective. The ability to give feedback is important for students so that they are able to effect change in the structure of placements when problems arise. Students noted that the placements which accepted constructive feedback were more beneficial learning environments.

\section{Questionnaire}

The full questionnaire is available in the Supplementary material. In the initial analysis, cross tabulation was performed for graduate versus undergraduate students and those who had been to the RCS and those who had not (Table 1).

Chi-square tests showed that there was no statistically significant difference between the groups, Fisher's exact test is 0.764 (all cases valid as there were no cells with a count $<5$ ). Hence for the rest of the analysis, we shall just look at differences between students who went to the RCS and those who did not.

Table I Graduate and undergraduate entry and numbers in rural clinical school (I year in penultimate year of medical course)

\begin{tabular}{llll}
\hline Medical students & $\begin{array}{l}\text { Did not spend } \\
\text { time in RCS }\end{array}$ & $\begin{array}{l}\text { Spent time in } \\
\text { RCS }\end{array}$ & Total \\
\hline Undergraduate & 24 & 11 & 35 \\
Graduate & 12 & 7 & 19 \\
Total & 36 & 18 & 54 \\
\hline
\end{tabular}

Abbreviation: RCS, rural clinical school.

\section{Overall educationally useful sites}

\section{Data interpretation}

Rural students rated regional hospitals and Indigenous health placements higher than metropolitan students did (Table 2 and Figure 1). Metropolitan students rated metropolitan GP placements and private practice rooms higher than rural students.

Using independent samples $t$-test, the differences between these two student groups only reached statistical significance for metropolitan general practices and regional hospitals. This suggests that medical students tend to give higher ratings to clinical placements they were exposed to more often. As their overall exposure is higher, the likelihood of a number of positive experiences should increase, resulting in an overall positive impact.

\section{Overall reasons why these clinical placements were seen as educationally useful to their clinical training \\ Data interpretation}

Overall, rural students most highly valued being part of a clinical team, high level of supervision, variety of patient presentations, working with junior doctors and the amount of formal teaching/bedside tutorials (Table 3). Metropolitan students most highly valued the amount of patient contact, having access to patient information, variety of patient presentations, working with junior doctors, being part of a clinical team/able to ask questions/clinical tutorials. Using independent samples $t$-test, the differences between these two student groups reached statistical significance in a few responses. Rural students were more likely to report the educational value of being part of a clinical team $(p<0.001)$, high level of supervision in training $(p=0.002)$. Metropolitan students were more likely to find a larger amount of patient contact $(p=0.01)$. This will be because they have

Table 2 Clinical training sites: students' perception of comparative educational value (5-point Likert scale)

\begin{tabular}{|c|c|c|c|c|}
\hline Placement & RCS students & Purely metro students & Combined & Independent samples $t$-test \\
\hline Metropolitan hospital (Level 3) wards & 4.22 & 4.33 & 4.3 & 0.503 \\
\hline Metropolitan hospital (Level 3) outpatient clinics & 3.72 & 3.56 & 3.61 & 0.468 \\
\hline $\begin{array}{l}\text { Allied health (e.g., physiotherapy, occupational therapy) } \\
\text { sessions }\end{array}$ & 2.56 & 2.83 & 2.74 & 0.508 \\
\hline Metropolitan general practice & 3.37 & 4.19 & 4 & 0.000 \\
\hline Rural general practice & 4.22 & 4.27 & 4.25 & 0.576 \\
\hline Regional hospital (Levels I and 2) & 4.76 & 4.22 & 4.49 & 0.039 \\
\hline Nursing attachments (e.g., to diabetes educator) & 2.89 & 2.68 & 2.75 & 0.491 \\
\hline Community placements (e.g., hospices, aged care homes) & 2.47 & 2.48 & 2.48 & 0.908 \\
\hline Private practice rooms & 2.80 & 3.39 & 3.22 & 0.097 \\
\hline Indigenous health placements & 4.30 & 3.66 & 3.98 & 0.061 \\
\hline
\end{tabular}

Abbreviation: RCS, rural clinical school. 


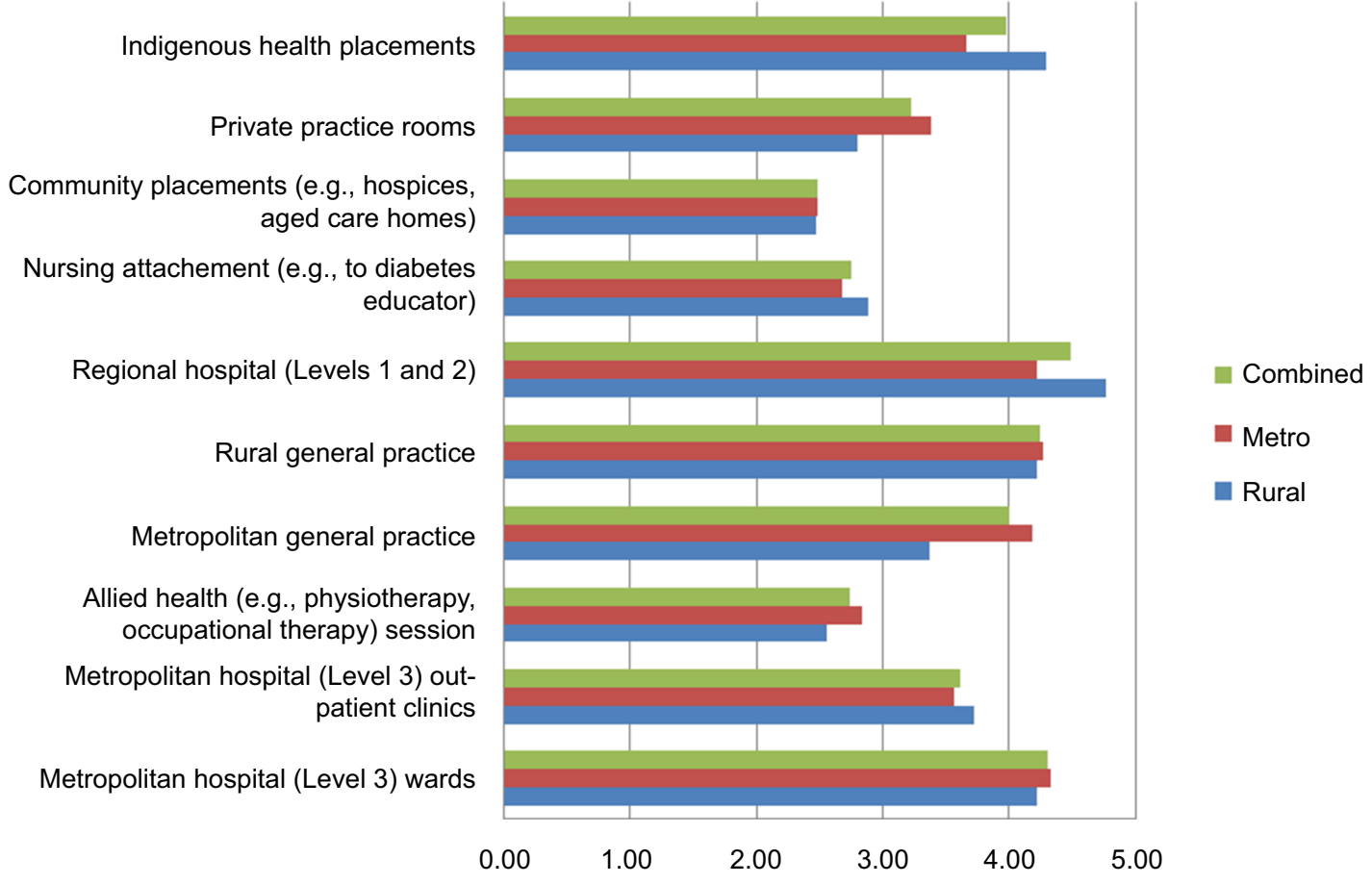

Figure I Clinical training sites: students' perception of comparative educational value (5-point Likert scale)

Table 3 Clinical training sites: reasons for students' perception of comparative educational value

\begin{tabular}{|c|c|c|c|c|}
\hline \multirow{2}{*}{$\begin{array}{l}\text { Why did you find this venue/these venues educationally useful to your } \\
\text { clinical training? (tick all that apply) } \\
\text { Answer options }\end{array}$} & \multicolumn{3}{|c|}{ Response count (\%) } & \multirow{2}{*}{$\begin{array}{l}\text { Independent samples } \\
\text { t-test } \\
\text { Differences between } \\
\text { rural and metro }\end{array}$} \\
\hline & Rural & Metro & Combined & \\
\hline Being part of a clinical team & 94.4 & 72.2 & 79.6 & 0.000 \\
\hline Amount of patient contact & 66.7 & 83.3 & 77.8 & 0.011 \\
\hline Various patient presentations & 77.8 & 75.0 & 75.9 & 0.438 \\
\hline Working with junior doctors (e.g., interns) & 77.8 & 75.0 & 75.9 & 0.438 \\
\hline High level of supervision in training & 83.3 & 63.9 & 70.4 & 0.002 \\
\hline Amount of formal bedside teaching/teaching ward rounds & 72.2 & 69.4 & 70.4 & 0.767 \\
\hline Amount of clinical tutorials with and without patients & 55.6 & 72.2 & 66.7 & 0.051 \\
\hline Opportunity to ask questions and receive useful information & 55.6 & 72.2 & 66.7 & 0.051 \\
\hline Having access to patient information on the site (laboratory and radiology results) & 44.4 & 77.8 & 66.7 & 0.023 \\
\hline Having peers to work with and share information/experiences & 55.6 & 63.9 & 61.1 & 0.436 \\
\hline Being on call with team to admit acute patients & 61.1 & 50.0 & 53.7 & 0.193 \\
\hline Regular feedback on progress in the clinical arena & 33.3 & 58.3 & 50.0 & 0.138 \\
\hline Centralized medical/clinical school sessions to consolidate learning & 33.3 & 41.7 & 38.9 & 0.505 \\
\hline Having good information services support including on-site library & 22.2 & 41.7 & 35.2 & 0.004 \\
\hline Having junior students to mentor and consolidate learning & 38.9 & 25.0 & 29.6 & 0.061 \\
\hline Frequent formative assessments (e.g., Mini-CEX, case reports) & 16.7 & 8.3 & II.I & 0.067 \\
\hline
\end{tabular}

larger health care institutions that they are attached to with more clinical units. These students also reported more clinical tutorials with and without patients and opportunities to ask questions and receive useful information ( $p=0.05)$. This will be related to the larger number of clinical teams and academic clinicians available at these institutions. Not surprisingly, the metropolitan students also reported more value from patient information access and information services present in the larger hospitals and university campus. Rural students had more value from mentoring junior students and interactive clinical assessments with their teachers.

As students were asked to indicate all the characteristics they found useful, this question helped to look at their overall perceptions. We did not ask them to weight their preferences. 


\section{The main clinical placement that students} found educationally useful to their clinical training

\section{Data interpretation}

Of those surveyed, the majority (56.6\%) thought Metropolitan Hospital (Level 3) wards were the most useful clinical placements for clinical training (Table 4A-C). This statistic was slightly higher in those students who studied in the metropolitan area $(60 \%)$ as opposed to those who studied in rural areas $(50 \%)$, but it remained high in both groups. There was a wider spread in the data among those students

Table 4A All students

\begin{tabular}{lll}
\hline $\begin{array}{l}\text { Which of the following clinical } \\
\text { placements did you find MOST } \\
\text { educationally useful to your clinical } \\
\text { training? (tick the most useful only) }\end{array}$ & $\begin{array}{l}\text { Response } \\
\text { (\%) }\end{array}$ & $\begin{array}{l}\text { Response } \\
\text { (n) }\end{array}$ \\
\hline $\begin{array}{l}\text { Metropolitan hospital (Level 3) wards } \\
\text { Rural general practice }\end{array}$ & 56.6 & 30 \\
Regional hospital (Levels I and 2) & 15.1 & 8 \\
$\begin{array}{l}\text { Other clinical placements } \\
\text { Metropolitan hospital (Level 3) outpatient }\end{array}$ & 7.5 & 6 \\
clinics & 5.7 & 4 \\
Allied Health (e.g., physiotherapy, & 1.9 & 3 \\
occupational therapy sessions) & 1.9 & 1 \\
$\begin{array}{l}\text { Private practice rooms } \\
\text { Nursing attachments (e.g., to diabetes }\end{array}$ & 0 & 1 \\
educator) & & 0 \\
Community placements (e.g., hospices, & 0 & 0 \\
aged care) & & \\
$\begin{array}{l}\text { Indigenous health placement } \\
\text { Metropolitan general practice }\end{array}$ & 0 & 0 \\
\hline
\end{tabular}

Notes: Clinical training sites: students' perception of highest educational value. One person did not answer this question; there were 53 responses in total for this question.

Table 4B Fully metropolitan students

\begin{tabular}{|c|c|c|}
\hline $\begin{array}{l}\text { Stratified data from metropolitan } \\
\text { students }\end{array}$ & $\begin{array}{l}\text { Response } \\
\text { (\%) }\end{array}$ & $\begin{array}{l}\text { Response } \\
\text { (n) }\end{array}$ \\
\hline Metropolitan hospital (Level 3) wards & 60.0 & 21 \\
\hline Other clinical placements & 11.4 & 4 \\
\hline Rural general practice & 8.6 & 3 \\
\hline $\begin{array}{l}\text { Metropolitan hospital (Level 3) } \\
\text { outpatient clinics }\end{array}$ & 8.6 & 3 \\
\hline Regional hospital (Levels I and 2) & 5.7 & 2 \\
\hline $\begin{array}{l}\text { Allied Health (e.g., physiotherapy, } \\
\text { occupational therapy sessions) }\end{array}$ & 2.9 & 1 \\
\hline Private practice rooms & 2.9 & I \\
\hline $\begin{array}{l}\text { Nursing attachments (e.g., to diabetes } \\
\text { educator) }\end{array}$ & 0 & 0 \\
\hline $\begin{array}{l}\text { Community placements (e.g., hospices, } \\
\text { aged care) }\end{array}$ & 0 & 0 \\
\hline Indigenous health placement & 0 & 0 \\
\hline Metropolitan general practice & 0 & 0 \\
\hline
\end{tabular}

Notes: Clinical training sites: students' perception of highest educational value. One person did not answer this question; there were 35 responses in total for this question.
Table 4C Students with I year in rural clinical school

\begin{tabular}{lll}
\hline Stratified data from rural students & $\begin{array}{l}\text { Response } \\
\text { (\%) }\end{array}$ & $\begin{array}{l}\text { Response } \\
\text { (n) }\end{array}$ \\
\hline Metropolitan hospital (Level 3) wards & 50.0 & 9 \\
Rural general practice & 27.8 & 5 \\
Regional hospital (Levels I and 2) & 22.2 & 4 \\
Other clinical placements & 0 & 0 \\
Metropolitan hospital (Level 3) & 0 & 0 \\
outpatient clinics & & \\
Allied health (e.g., physiotherapy, & 0 & 0 \\
occupational therapy sessions) & & \\
$\begin{array}{l}\text { Private practice rooms } \\
\text { Nursing attachments (e.g., to diabetes }\end{array}$ & 0 & 0 \\
educator) & 0 & 0 \\
Community placements (e.g., hospices, & 0 & 0 \\
aged care) & & \\
Indigenous health placement & 0 & 0 \\
Metropolitan general practice & 0 & 0 \\
\hline Note: Clinical training sites: students' perception of highest educational value.
\end{tabular}

who studied in the metropolitan area with seven different options scoring at least one vote. This was not seen in the rural students, who divided their responses between rural general practice and regional hospitals (Levels 1 and 2) if they did not choose metropolitan hospital (Level 3) wards as their preferred clinical placement.

\section{The most educationally useful clinical placement to clinical training Data Interpretation}

The main reason students found their preferred clinical placement useful was because of the amount of patient contact $(84.9 \%)$ and this did not matter if they were a metropolitan student $(82.9 \%)$ or a rural student $(88.9 \%)$, although this figure was higher in the rural students (Table 5A-C). The next two highest responses were also the same for both groups of students, being access to a variety of patient presentations and being part of a clinical team. There were differences in the remaining responses but no significant discrepancies between the two groups. A lower student/teacher ratio was an important point to note in rural placements, as pointed out by one student. Reasons that were not as influential on the educational usefulness of venues included frequent formative assessments and centralized medical/clinical school sessions to consolidate learning.

\section{Opportunities to enhance learning in clinical placements Data interpretation}

The learning opportunities that students experienced most frequently were attending postgraduate teaching sessions, 
Table 5A All students

\begin{tabular}{|c|c|c|}
\hline $\begin{array}{l}\text { Why did you find this venue the } \\
\text { most educationally useful to your } \\
\text { clinical training? (tick all that apply) }\end{array}$ & $\begin{array}{l}\text { Response } \\
\text { (\%) }\end{array}$ & $\begin{array}{l}\text { Response } \\
\text { (n) }\end{array}$ \\
\hline Amount of patient contact & 84.9 & 45 \\
\hline Various patient presentations & 83.0 & 44 \\
\hline Being part of a clinical team & 66.0 & 35 \\
\hline $\begin{array}{l}\text { Opportunity to ask questions and receive } \\
\text { useful information }\end{array}$ & 62.3 & 33 \\
\hline High level of supervision in training & 60.4 & 32 \\
\hline $\begin{array}{l}\text { Amount of formal bedside teaching/ } \\
\text { teaching ward rounds }\end{array}$ & 58.5 & 31 \\
\hline $\begin{array}{l}\text { Amount of clinical tutorials with and } \\
\text { without patients }\end{array}$ & 50.9 & 27 \\
\hline Working with junior doctors (e.g., interns) & 43.4 & 23 \\
\hline $\begin{array}{l}\text { Regular feedback on progress in the } \\
\text { clinical arena }\end{array}$ & 41.5 & 22 \\
\hline $\begin{array}{l}\text { Having peers to work with and share } \\
\text { information/experiences }\end{array}$ & 39.6 & 21 \\
\hline $\begin{array}{l}\text { Having access to patient information on } \\
\text { the site (laboratory and radiology results) }\end{array}$ & 39.6 & 21 \\
\hline $\begin{array}{l}\text { Being on call with team to admit acute } \\
\text { patients }\end{array}$ & 37.7 & 20 \\
\hline $\begin{array}{l}\text { Having junior students to mentor and } \\
\text { consolidate learning }\end{array}$ & 22.6 & 12 \\
\hline $\begin{array}{l}\text { Centralized medical/clinical school } \\
\text { sessions to consolidate learning }\end{array}$ & 20.8 & 11 \\
\hline $\begin{array}{l}\text { Having good information services support } \\
\text { including on-site library }\end{array}$ & 15.1 & 8 \\
\hline $\begin{array}{l}\text { Frequent formative assessments } \\
\text { (e.g., Mini-CEX, case reports) }\end{array}$ & 9.4 & 5 \\
\hline Other reason(s) & 1.89 & I \\
\hline
\end{tabular}

Notes: Clinical training sites: reasons for students' perception of educational value. One person did not answer this question; there were 53 responses in total for this question.

followed by attending intern training sessions, participating in teaching ward rounds and presenting acute patients to a senior doctor (Table 6). The least frequent learning opportunities were the online-based blogs and forums.

In terms of rural and metropolitan differences, rating averages were fairly comparable with no startling differences. Metropolitan students did record slightly higher rating averages when there was a difference, except reporting daily on a patients' progress where rural students had a higher rating average.

The activities which rated highly, included participation on ward rounds and engagement with clinical teachers (Table 7). Attending postgraduate learning sessions for interns and residents also rated highly. Interestingly, reviewing online cases was rated highly but the other online sources of learning (participating in learning blogs and Facebook page) were at the lower end of the scale. This is likely because these activities were rare and therefore not developed sufficiently to be of value. In terms of differences
Table 5B Fully metropolitan students

\begin{tabular}{lll}
\hline $\begin{array}{l}\text { Stratified data from metropolitan } \\
\text { students }\end{array}$ & $\begin{array}{l}\text { Response } \\
\text { (\%) }\end{array}$ & $\begin{array}{l}\text { Response } \\
\text { (n) }\end{array}$ \\
\hline $\begin{array}{l}\text { Amount of patient contact } \\
\text { Various patient presentations }\end{array}$ & 82.9 & 29 \\
$\begin{array}{l}\text { Opportunity to ask questions and receive } \\
\text { useful information }\end{array}$ & 65.7 & 29 \\
$\begin{array}{l}\text { Being part of a clinical team } \\
\text { High level of supervision in training }\end{array}$ & 62.9 & 22 \\
$\begin{array}{l}\text { Amount of formal bedside teaching/ } \\
\text { teaching ward rounds }\end{array}$ & 57.1 & 20 \\
$\begin{array}{l}\text { Amount of clinical tutorials with and } \\
\text { without patients }\end{array}$ & 54.3 & 20 \\
$\begin{array}{l}\text { Working with junior doctors (e.g., interns) } \\
\text { Having access to patient information on } \\
\text { the site (laboratory and radiology results) }\end{array}$ & 45.7 & 19 \\
$\begin{array}{l}\text { Regular feedback on progress in the } \\
\text { clinical arena }\end{array}$ & 40.9 & 16 \\
$\begin{array}{l}\text { Having peers to work with and share } \\
\text { information/experiences }\end{array}$ & 37.1 & 14 \\
$\begin{array}{l}\text { Being on call with team to admit acute } \\
\text { patients }\end{array}$ & 37.1 & 13 \\
$\begin{array}{l}\text { Centralized medical/clinical school } \\
\text { sessions to consolidate learning }\end{array}$ & 22.9 & 8 \\
$\begin{array}{l}\text { Having junior students to mentor and } \\
\text { consolidate learning } \\
\text { Having good information services support }\end{array}$ & 17.1 & 6 \\
$\begin{array}{l}\text { Frcluding on-site library } \\
\text { Frequent formative assessments (e.g., }\end{array}$ & 11.4 & 4 \\
$\begin{array}{l}\text { Mini-CEX, case reports) } \\
\text { Other reason(s) }\end{array}$ & 0.0 & 4 \\
\hline Notes: Clica tranng stes rean for sudens & & 0 \\
\hline
\end{tabular}

Notes: Clinical training sites: reasons for students' perception of educational value. One person did not answer this question; there were 35 responses in total for this question.

between rural and metropolitan learning, again, there were no obvious differences in rating averages for the different learning activities.

\section{Assessments \\ Data interpretation}

Of the data collected from the 54 people surveyed, short case examinations were the most frequently used assessment of clinical knowledge with a rating average of 3.91 (Table 8). This was closely followed by continuous performance assessments and long case examinations with rating averages of 3.83 and 3.76, respectively. The only two forms of assessment that were infrequent among those surveyed were portfolios (rating average of 2.41) and oral (non-patient-based) examinations (rating average of 2.61).

\section{Discussion}

Previous studies investigating the factors that are most important in creating effective learning environments for junior doctors found that the level of participation students 
Table 5C Students with I year in rural clinical school

\begin{tabular}{|c|c|c|}
\hline Stratified data from rural students & $\begin{array}{l}\text { Response } \\
\text { (\%) }\end{array}$ & $\begin{array}{l}\text { Response } \\
\text { (n) }\end{array}$ \\
\hline Amount of patient contact & 88.9 & 16 \\
\hline Various patient presentations & 83.3 & 15 \\
\hline Being part of a clinical team & 72.2 & 13 \\
\hline High level of supervision in training & 66.7 & 12 \\
\hline $\begin{array}{l}\text { Amount of formal bedside teaching/ } \\
\text { teaching ward rounds }\end{array}$ & 61.1 & 11 \\
\hline $\begin{array}{l}\text { Opportunity to ask questions and receive } \\
\text { useful information }\end{array}$ & 55.6 & 10 \\
\hline $\begin{array}{l}\text { Amount of clinical tutorials with and } \\
\text { without patients }\end{array}$ & 44.4 & 8 \\
\hline $\begin{array}{l}\text { Regular feedback on progress in the } \\
\text { clinical arena }\end{array}$ & 44.4 & 8 \\
\hline $\begin{array}{l}\text { Having peers to work with and share } \\
\text { information/experiences }\end{array}$ & 44.4 & 8 \\
\hline Working with junior doctors (e.g., interns) & 38.9 & 7 \\
\hline $\begin{array}{l}\text { Being on call with team to admit acute } \\
\text { patients }\end{array}$ & 38.9 & 7 \\
\hline $\begin{array}{l}\text { Having junior students to mentor and } \\
\text { consolidate learning }\end{array}$ & 33.3 & 6 \\
\hline $\begin{array}{l}\text { Having access to patient information on } \\
\text { the site (laboratory and radiology results) }\end{array}$ & 33.3 & 6 \\
\hline $\begin{array}{l}\text { Having good information services support } \\
\text { including on-site library }\end{array}$ & 22.2 & 4 \\
\hline $\begin{array}{l}\text { Centralized medical/clinical school sessions } \\
\text { to consolidate learning }\end{array}$ & 16.7 & 3 \\
\hline $\begin{array}{l}\text { Frequent formative assessments (e.g., } \\
\text { Mini-CEX, case reports) }\end{array}$ & 5.6 & 1 \\
\hline Other reason(s) - high student/teacher ratio & 5.6 & I \\
\hline
\end{tabular}

Table 6 Frequencies of activities in clinical placements (5-point Likert scale)

\begin{tabular}{|c|c|c|c|}
\hline $\begin{array}{l}\text { Frequency of activities in clinical } \\
\text { placements }\end{array}$ & Combined & Rural & Metro \\
\hline Present acute patients to a senior doctor & 3.39 & 3.39 & 3.39 \\
\hline $\begin{array}{l}\text { Report daily on your allocated patients' } \\
\text { progress }\end{array}$ & 2.70 & 2.78 & 2.67 \\
\hline Participate in teaching ward rounds & 3.44 & 3.44 & 3.44 \\
\hline Attend intern training sessions & 3.74 & 3.72 & 3.75 \\
\hline Attend resident training sessions & 3.06 & 3.00 & 3.08 \\
\hline $\begin{array}{l}\text { Attend postgraduate sessions including } \\
\text { Grand Rounds }\end{array}$ & 3.87 & 3.67 & 3.97 \\
\hline $\begin{array}{l}\text { Review specifically prepared online cases } \\
\text { to consolidate learning }\end{array}$ & 2.93 & 2.67 & 3.06 \\
\hline $\begin{array}{l}\text { Participate in learning blogs supervised by } \\
\text { a clinician }\end{array}$ & 1.40 & 1.12 & 1.53 \\
\hline $\begin{array}{l}\text { Participate in learning blogs with other } \\
\text { students only }\end{array}$ & 1.51 & 1.24 & 1.64 \\
\hline $\begin{array}{l}\text { Participate in a dedicated Facebook page } \\
\text { for learning issues }\end{array}$ & 1.09 & 1.06 & 1.11 \\
\hline
\end{tabular}

are afforded in the workplace is key in clinical practice learning. ${ }^{5}$ It has been established that greater participation in the workplace facilitates greater confidence and competency, especially in clinical practice. ${ }^{5,6}$ This can be directly
Table 7 Educational value of clinical activities (5-point Likert scale)

\begin{tabular}{|c|c|c|c|}
\hline Activities & Combined & Rural & Metro \\
\hline Present acute patients to a senior doctor & 4.77 & 4.89 & 4.71 \\
\hline $\begin{array}{l}\text { Report daily on your allocated patients' } \\
\text { progress }\end{array}$ & 4.19 & 4.41 & 4.06 \\
\hline Participate in teaching ward rounds & 4.19 & 4.50 & 4.03 \\
\hline Attend intern training sessions & 4.22 & 4.00 & 4.33 \\
\hline Attend resident training sessions & 3.79 & 3.53 & 3.93 \\
\hline $\begin{array}{l}\text { Attend postgraduate sessions including } \\
\text { Grand Rounds }\end{array}$ & 3.38 & 3.35 & 3.40 \\
\hline $\begin{array}{l}\text { Review specifically prepared online } \\
\text { cases to consolidate learning }\end{array}$ & 3.94 & 3.86 & 3.97 \\
\hline $\begin{array}{l}\text { Participate in learning blogs supervised } \\
\text { by a clinician }\end{array}$ & 2.67 & 2.33 & 2.78 \\
\hline $\begin{array}{l}\text { Participate in learning blogs with other } \\
\text { students only }\end{array}$ & 2.57 & 2.33 & 2.64 \\
\hline $\begin{array}{l}\text { Participate in a dedicated Facebook page } \\
\text { for learning issues }\end{array}$ & 1.89 & 1.00 & 2.00 \\
\hline
\end{tabular}

correlated with the responses given by those students who participated in RCS as they were able to experience a greater level of involvement in patient care compared to metropolitan students. This is supported by findings that students who participate in extended rural clinical placements perform better than their metropolitan counterparts in academic performance. $^{7}$

\section{Clinics and bedside tutorials}

These are important learning opportunities for students as they are able to observe experienced clinicians and receive constructive feedback helping develop their clinical skills. ${ }^{8}$ Students also require teaching in real clinical settings, as these experiences encourage skills which are required in the real clinical environment. ${ }^{8}$ Problem-based learning tutorials were not identified as being educationally useful, with bedside tutorials being preferred instead. Tutorials in a clinical setting also allow for topics relevant to professional development to be taught, such as ethical issues, communication and teamwork. ${ }^{8}$

\section{Assessments}

When assessments do not align with curricular goals, they tend to cause increased student stress and only a surface approach to learning, leading to a deterioration in learning outcomes. ${ }^{9}$ Assessments should encourage students to remain lifelong learners, as it is impossible to learn everything in medicine, so the important learning points should be emphasized and provide a general knowledge base, allowing focused learning to be undertaken in postgraduate courses, where it is relevant to their career path. Another point about assessments was that there seemed to be too many and this made 
Table 8 Frequencies of assessments during clinical placements

\begin{tabular}{|c|c|c|c|c|c|c|}
\hline $\begin{array}{l}\text { In your clinical rotations, how frequently } \\
\text { were the following assessments used to } \\
\text { examine your clinical knowledge? }\end{array}$ & I - Never & $\begin{array}{l}\text { 2- Rarely } \\
(<10 \%)\end{array}$ & $\begin{array}{l}3 \text { - Some } \\
\text { rotations } \\
(10 \%-45 \%)\end{array}$ & $\begin{array}{l}4-\text { Most } \\
\text { rotations } \\
(50 \%-90 \%)\end{array}$ & $\begin{array}{l}5 \text { - Every } \\
\text { rotation }\end{array}$ & $\begin{array}{l}\text { Rating } \\
\text { average }\end{array}$ \\
\hline Short case examinations & 0 & 0 & 16 & 27 & II & 3.91 \\
\hline Continuous performance assessment & 3 & 7 & 6 & 18 & 20 & 3.83 \\
\hline Long case examinations & 0 & 0 & 21 & 25 & 8 & 3.76 \\
\hline Logbooks & 0 & 4 & 13 & 32 & 5 & 3.70 \\
\hline Paper-based exams & 2 & 9 & 23 & 11 & 9 & 3.30 \\
\hline $\begin{array}{l}\text { Objective structured clinical examinations/multiple } \\
\text { station assessment tasks }\end{array}$ & 4 & 8 & 21 & 15 & 6 & 3.20 \\
\hline Oral (non-patient based) examinations & II & 14 & 17 & 9 & 3 & 2.61 \\
\hline Portfolios & 13 & 16 & 16 & 8 & I & 2.41 \\
\hline
\end{tabular}

the focus of each rotation how to pass the exam, rather than what can be learnt on the rotation. The variety of learning environments means that every student will have unique learning experiences while at university, so it is important to ensure that they all have the foundation to be able to practice medicine once they graduate.

Increasing numbers of medical students in recent years have posed a challenge to traditional teaching methods employed in the hospital environment. Determining the most educationally useful learning environments for students in their clinical training is important so that time and resources can be effectively allocated. In this study, two focus groups were conducted, and the responses of final year medical students to a questionnaire regarding which placements students find most educationally useful and what aspects of these placements they most highly valued were analyzed.

In response to the questionnaire, students rated metropolitan hospital wards as the most educationally useful clinical placement, rating higher than rural general practice and regional hospital placements combined. The stratified data finds that this is more obvious with metropolitan students. Metropolitan hospital wards ranked highest among rural clinical students but were also equal to rural general practice and regional hospital placements when combined.

These results found that students perceived metropolitan hospital wards as the most educationally useful, although they experienced more clinical problems, conditions and procedures in the rural setting. Students tended to rate the placements they were more frequently exposed to more highly than those they avoided. Statistically significant differences between rural and metropolitan students in preferred clinical placements were that rural students rated regional hospitals more than their counterparts and metropolitan students favored metropolitan general practice more than rural students. There were high nonapplicable ratings among metropolitan students for regional hospitals and indigenous health placements $(50 \%)$, while rural students rated these placements consistently very useful. This finding is encouraging as there is a positive response from students who experience rural placements, so metropolitan students may benefit from increased rural exposure in these settings.

\section{Educational impact of rural training}

The main differences between rural and metropolitan clinical training experiences were that rural students were able to:

1. Interact with doctors on a closer basis professionally and socially.

2. Develop a long-term relationship with doctors (metropolitan students change rotations every 8 weeks, while RCS students have more continuous contact with the same doctors).

3. Enjoy a smaller student-doctor ratio.

4. Work with doctors who were more invested in students' learning.

5. Generate a greater rapport with patients and be involved in their follow-up.

These findings are consistent with other studies, identifying that rural students are able to play a more significant role in evaluation and treatment of patients. ${ }^{14}$ Studies have found that rural students and those in rural rotations do just as well and often better than metropolitan counterparts. ${ }^{15,16}$ There is evidence that students who participate in rural clinical placements are not at a disadvantage academically compared to metropolitan students, with a study involving students attending the University of Queensland showing comparable academic performance among cohorts from 2002 to 2004 between rural and urban students. ${ }^{20}$ Rural primary care settings have been associated with providing increased clinical exposure to common clinical conditions and the opportunity to develop procedural skills compared to metropolitan hospital settings. ${ }^{21}$ Rural students tend to see a wider variety of 
patients and encounter more clinical problems and conditions than metropolitan students, and participate in more clinical procedures. ${ }^{16}$ This is in contrast with the view that students in rural placements may be compromised academically due to their reduced exposure to a high concentration of academic medical practitioners.

The more favorable student-patient and student-clinician ratios in rural placements allow for greater student participation in clinical settings. Previous studies investigating the factors that are most important in creating effective learning environments for junior doctors found that the level of participation students are afforded in the workplace is key in clinical practice learning. ${ }^{9}$ It has been established that greater participation in the workplace facilitates greater confidence and competency, especially in clinical practice. ${ }^{1,9}$ This can be directly correlated with the responses given by those students who participated in RCS as they were able to experience a greater level of involvement in patient care compared to metropolitan students. One study even suggested that students who participate in extended rural clinical placements perform better than their metropolitan counterparts in academic performance. ${ }^{15}$

Rural students appreciated being part of a clinical team and a high level of supervision as being important factors in clinical placements. This is consistent with the focus group findings, as students in RCS were able to interact with doctors on a closer basis and were included as a part of the team, whereas one complaint metropolitan students had was that some teams would be uninterested in students, which led to them being left out of clinical activities at times and miss important learning opportunities.

A finding in both focus groups was that business ward rounds were often of little benefit to students, due to time constraints and not being able to participate. As the clinical setting allows for integration of theoretical knowledge and practical skills, ward rounds can be very effective in increasing students' interest and motivation to learn, as identified by Murdoch and Cottrell. ${ }^{22}$ Possible opportunities for improvement of ward round teaching, may include the following:

1. Having weekly teaching ward rounds.

2. Having one doctor who is directly involved in teaching on the patient.

3. Encouraging active participation is important - students can do presentations on subjects which are focal points for the round, e.g., nutrition, fluid management, drug interactions.

4. Discussing one patient in depth/clinical teaching session.
Bedside tutorials were rated highly by all students, as they provide learning opportunities where students can observe the technique of experienced clinicians in examining patients and receive constructive feedback helping to develop their clinical skills. Students also require teaching in real clinical settings, as these experiences encourage skills which are required in the real clinical environment. ${ }^{22}$ In our study, problem-based learning tutorials however were not identified as being educationally useful, with bedside tutorials being preferred instead, due to the more practical clinical component. Tutorials in a clinical setting also allow for topics relevant to professional development to be taught, such as ethical issues, communication and teamwork. ${ }^{22}$

Outpatient clinics can function as an appropriate setting for clinical teaching, but received a mixed response in the focus groups. Students felt that they were only effective when they were allowed to see the patient one-on-one, formulate their own diagnosis and management plan and then discuss with the treating doctor. Outpatient learning can be improved by the teacher setting goals for students, asking them questions, selecting one general teaching point with each patient, priming the student prior to each patient and providing feedback. ${ }^{23}$ Subsequent feedbacks from academic clinicians suggest that the high pressure of service delivery in the health care system in metropolitan hospitals, do not allow adequate time for individual or dual student-patient interactions and supervisor observation, that could enhance the learning experience.

Being on call with teams to admit acute patients was rated surprisingly low by students, both rural and metropolitan. Traditionally, students have spent more time "on-call" with admitting teams, as it allows them to be more involved in clerking patients and develop competency in acute management decisions. ${ }^{22}$ The low ratings may be due to students not being able to organize enough time to be with the team when they are on call because it is not a course requirement. More course-structured learning where students are with the admitting teams, may help to increase the amount of learning students' experience in the acute setting. The other issue may be that much of acute care learning is opportunistic and students may not be prepared to spend long hours hoping to learn or practice on patients, when their time could be more usefully spent learning the vast amount of information and knowledge they need for their assessments. The other issue brought up in the questionnaire is the dilution of actual clinical time by compulsory written assignments that students have to do in each rotation. There is a place of using mobile devices like tablets to document clinical encounters that could be logged as artifacts in an e-portfolio to keep students at the clinical interface. 
Furthermore, students in this study, felt that assessments were often too specialized and failed to test general concepts, instead focusing on specialist knowledge which would draw their attention away from clinical learning with patients. As stated by Bloomfield et al, when assessments do not align with curricular goals, they tend to cause increased student stress and only a surface approach to learning, leading to deterioration in retention of learning outcomes. ${ }^{24}$ Assessments should encourage students to remain lifelong learners, as it is impossible to learn everything in medicine, so the important learning points should be emphasized and provide a general knowledge base, allowing focused learning to be undertaken in postgraduate courses, where it is relevant to their career path. Another point about assessments was that there seemed to be too many and this made the focus of each rotation how to pass the exam, rather than what can be learnt on the rotation. The variety of learning environments means that every student will have unique learning experiences while at university so it is important to ensure that they all have the fundamental knowledge and skills to be able to practice medicine once they graduate.

A 2010 Australian study that used data from Flinders University Parallel Rural Community Curriculum had "how to expand the venues for clinical training without compromising the quality of clinical education" as a main outcome measure, found that students commonly perceived that their colleagues at other learning sites were better off in terms of their learning. ${ }^{25}$ This relates to the proverb that "the grass is greener on the other side". Our study finds that this does not hold true when comparing the learning opportunities and frequency of clinical activities at metropolitan and rural placements. The opportunities for clinical activities are very similar if not the same for rural and metropolitan students.

\section{Conclusion}

In summary, students reported that the main factors that made clinical placements useful in their learning were the amount of patient contact, seeing a variety of patient presentations and being part of a clinical team. These are core features of clinical learning, which are necessary for the development of skills and knowledge for medical students and are key for effective learning in the clinical environment.

\section{Limitations of study}

This study depended on the student willingness to participate. Medical students are prone to research and survey fatigue as evaluation demands placed on them by the university and their student society are quite onerous. It was important to note that we had a $33.8 \%$ response rate overall after four email-outs, which is compatible to international studies. ${ }^{26}$ We followed the ethics protocol strictly, so that there was no attempt made to ask the students to answer the questionnaire by direct contact with them or with paper copies. We did note that as each group of students responded to this questionnaire, the overall analysis for each section did not change, suggesting that the perceptions of rural and metropolitan students were overall consistent throughout this study.

One result of this study is that students rated metropolitan hospital wards as the most educationally useful clinical placement. It actually rates higher than rural general practice and regional hospital placements combined. Our stratified data finds that this is consistent with metropolitan students. For rural students, metropolitan hospital wards also rank the highest but are ranked the equal highest if rural general practice and regional hospital placements are combined. This may have changed if all students had exposure to regional hospital placements.

As this study examined perceived value, it will be interesting to look at comparisons of actual academic performances of rural medical students versus metropolitan students. A cohort study of medical students from Flinders University found that the concern that student academic performance in the tertiary hospital would be better than that of students in the regional hospital and community settings is not justified. ${ }^{15}$

These students perceived metropolitan hospital wards as the most educationally useful, although students experience more patients with different clinical problems, conditions and procedures in rural settings. What impact this has on students' academic performance and competency as junior doctors requires further exploration.

Using the Kirkpatrick model, this study is at Level 1 , as it effectively was investigating medical students' reactions to their clinical training program ${ }^{27}$ However the results can have a more encompassing effect. Consumer perception and engagement is an important assessment of an organization's performance and differences within a clinical educational program can be used to identify strengths that can be encouraged and weaknesses that need to be addressed. The impact of this can even lead to broader educational changes which maximizes the perceptually good programs that can lead to better learning measures (Kirkpatrick Level2), behavioral outcomes (Kirkpatrick Level 3) and organizational changes (Kirkpatrick Level 4). ${ }^{27}$ However Kirkpatrick's model does have limitations as it can incompletely identify advances if the learning transfer process is not incorporated. Also the assumption 
of causality may not be valid if multiple variables are not incorporated to explain the impact on learning measures and behavioral outcomes. ${ }^{28}$ Systematically obtaining regular feedback from students and clinicians can enhance all levels of clinical training outcome measures.

\section{Acknowledgments}

The author acknowledges the contributions of medical students David White, Zacharia Joseph and Anthony Vu in participating in the implementation of this research project; and the students who participated in the Focus groups and online questionnaires. The author also acknowledges the support of Medical Deans Australia and New Zealand in facilitating the online data collection.

\section{Disclosure}

The author reports no conflicts of interest in this work.

\section{References}

1. Sheehan D, Wilkinson T, Paltridge D. A tool to evaluate effective learning environments within clinical attachments for interns. Focus Health Prof Educ. 2008;10(1):1-10.

2. Joyce C, McNeil J, Stoelwinder J. More doctors, but not enough: Australian medical workforce supply 2001. Med JAust. 2006;184(9):441-446.

3. Kirchner S, Roberts-Thomson R [webpage on the Internet]. Australia to Lose Out on New Doctors. 2010. Available from: https://www.amsa. org.au/node/1069. Accessed January 2, 2017.

4. Medical Deans Australia and New Zealand. National Clinical Training Review. 2008. Available from: http://www.medicaldeans.org.au/ wp-content/uploads/National-Clinical-Training-Review.pdf. Accessed January 2, 2017.

5. Sheehan D, Wilkinson T. Maximising the clinical learning of junior doctors: applying educational theory to practice. Med Teach. 2007;29:827-829.

6. Al Kadri HMF, Al-Moamary MS, Elzubair M, et al. Exploring factors affecting undergraduate medical students' study strategies in the clinical years: a qualitative study. Adv Health Sci Educ. 2011;16:553-567.

7. Marrow C, Tatum S. Student supervision: myth or reality? JAdv Nurs. 1994;19(6):1247-1255.

8. Sheehan D, Bagg W, de Beer W, et al. The good apprentice in medical education. N Z Med J. 1308;2010:123.

9. Billett S. Learning in the Workplace: Strategies for Effective Practice. Sydney: Allen and Unwin; 2001.
10. Redlich PN, Milkowski T, Bragg D, Biernat K, Winthrop A, Simpson D. Multiple variables influence the educational value of surgical clerkship sites. Am J Surg. 2006;191:178-182.

11. Hannon F. A national medical education needs' assessment of interns and the development of an intern education and training programme. Med Educ. 2000;34:275-284.

12. Wilson NW, Bouhuijs PAJ, Conradie HH, Reuter H, Van Heerden BB, Marais BJ. Perceived educational value and enjoyment of a rural clinical rotation for medical students. Rural Remote Health. 2008;8(3):999.

13. Eley DS, Young L, Wilkinson D, Chater AB, Baker PG. Coping with increasing numbers of medical students in rural clinical schools: options and opportunities. Med J Aust. 2008;188(11):669-671.

14. Barrett FA, Lipsky MS, Lutfiyya MN. The impact of rural training experiences on medical students: a critical review. Acad Med. 2011;86(2): 259-263.

15. Worley P, Esterman A, Prideaux D. Cohort study of examination performance of undergraduate medical students learning in community settings. BMJ. 2004;328(7433):207-209.

16. Kamien M. A comparison of medical student experiences in rural specialty and metropolitan teaching hospital practice. Aust J Rural Health. 1996;4(3):151-158.

17. Newble DI, Jaeger K. The effect of assessments and examinations on the learning of medical students. Med Educ. 1983;17:165-171.

18. Guest G, MacQueen K, Namey EE. Applied Thematic Analysis. New York: Sage Publications Inc; 2012.

19. Braun V, Clarke V. Using thematic analysis in psychology. Qual Res Psychol. 2006;3(2):77-101.

20. Waters B, Hughes J, Forbes K, Wilkinson D. Comparative academic performance of medical students in rural and urban clinical settings. Med Educ. 2006;40(2):117-120.

21. Worley P, Strasser R, Prideaux D. Can medical students learn specialist disciplines based in rural practice: lessons from students' self reported experience and competence. Rural Remote Health. 2004;4:338

22. Murdoch ED, Cottrell D. Maximising the effectiveness of undergraduate teaching in the clinical setting. Arch Dis Child. 1998;79(4):365-367.

23. McGee SR, Irby DM. Teaching in the outpatient clinic. J Gen Intern Med. 1997;12:34-40.

24. Bloomfield L, Harris P, Hughes C. What do students want? The types of learning activities preferred by final year medical students. Med Educ. 2003;37(2):110-118.

25. Couper I, Worley P. Meeting the challenges of training more medical students: lessons from Flinders University's distributed medical education program. Med J Aust. 2010;193(1):34-36.

26. Cook C, Heath F, Thompson RL. A meta-analysis of response rates in web- or internet-based surveys. Educ Psychol Meas. 2000;60(6):821-836.

27. Kirkpatrick DL. Evaluation of Training. In: Craig RL, editor. Training and Development Handbook: A Guide to Human Resource Development. New York: McGraw Hill; 1976.

28. Bates R. A critical analysis of evaluation practice: the Kirkpatrick model and the principle of beneficence. Eval Program Plann. 2004;27:341-347.
Advances in Medical Education and Practice

\section{Publish your work in this journal}

Advances in Medical Education and Practice is an international, peerreviewed, open access journal that aims to present and publish research on Medical Education covering medical, dental, nursing and allied health care professional education. The journal covers undergraduate education, postgraduate training and continuing medical education

\section{Dovepress}

including emerging trends and innovative models linking education, research, and health care services. The manuscript management system is completely online and includes a very quick and fair peer-review system. Visit http://www.dovepress.com/testimonials.php to read real quotes from published authors. 